\title{
GEOGRAFIA DOS SONS NÃO ESQUIZOFÔNICOS NA REGIÃO DO RECIFE: CULTURA POPULAR E COTIDIANO URBANO
}

\author{
GÉOGRAPHIE DES SONS NON SCHIZOPHONIQUES DANS LA RÉGION \\ DU RECIFE : CULTURE POPULAIRE ET QUOTIDIEN URBAIN
}

\author{
GEOGRAPHY OF NONSCHIZOPHONIC SOUNDS IN THE REGION \\ OF RECIFE: POPULAR CULTURE AND URBAN DAILY LIFE
}

\author{
Cristiano Nunes Alves - Universidade Estadual de Campinas - Campinas - São Paulo - Brasil \\ cris7cris7@yahoo.com.br
}

\begin{abstract}
Resumo
Este artigo aborda a espessura de manifestações da cultura popular recifense, os chamados sons não esquizofônicos, surgidos e disseminados a despeito das possibilidades técnicas que constituem o fenômeno da esquizofonia - o rompimento entre a origem e a emissão sonora. Durante a pesquisa, foram fundamentais, além do levantamento bibliográfico, os trabalhos de campo: visitas técnicas e entrevistas semiestruturadas. Foram abordadas a tipologia e a topologia das manifestações não esquizofônicas no Recife, abrigadas, sobretudo, na periferia metropolitana. Enfocou-se o recente adensamento em torno do maracatu na capital pernambucana, e esmiuçaram-se os nexos entre cultura popular e paisagem sonora no bairro dos Coelhos. Trata-se de uma análise do território usado, lançando um olhar sobre o cotidiano de uma metrópole marcada, a um só tempo, tanto por desigualdade socioterritorial, quanto por riqueza e diversidade culturais.

Palavras-chave: Uso do Território, Cultura Popular, Esquizofonia, Paisagem Sonora, Recife.
\end{abstract}

\section{Resumé}

Cet article aborde l'épaisseur des manifestations de la culture populaire du Recife connues sous le nom de sons non schizophoniques, émergés et disséminés malgré les possibilités techniques qui constituent le phénomène de l'schizophonie - la coupure entre la source et l'émission sonore. En plus de la littérature, le travail de terrain, comme des visites techniques et des entretiens semi-structurés, a aussi été fondamental pour cette recherche. Attention a été donnée à la typologie et à la topologie des manifestations non schizophoniques à Recife, lesquelles se trouvent, spécialment, dans la périphérie métropolitaine. On a concentré sur la intensification récente du maracatu à Recife, en analysant les liens entre la culture populaire et le paysage sonore dans le quartier des Coelhos. II s'agit d'une analyse du territoire utilisé, jetant les yeux sur la vie quotidienne d'une métropole marquée, en même temps, par inégalité socio-territoriale et par richesse et diversité culturelles.

Mots-clés: Usage du territoire, Culture populaire, Schizophonie, Paysage Sonore, Recife.

\begin{abstract}
This article deals with the density of Recife's popular culture manifestations known as nonschizophonic sounds, which emerged and disseminated despite the technical possibilities that constitute the schizophonic phenomenon - the splitting of the original sound and its acoustic reproduction. In addition to bibliographical searches, extensive fieldwork such as technical visits and semistructured interviews were also fundamental to this research. Attention was drawn upon the typology and the topology of Recife's nonschizophonic manifestations, found especially within the metropolitan periphery. A special focus was given to the recent intensification of maracatu in Recife, analyzing the connections between popular culture and soundscape in the Coelhos neighborhood. This is an analysis of the used territory, looking into the daily life of a metropolis marked simultaneously by socio-territorial inequality and by cultural richness and diversity. Keywords: Use of Territory, Popular Culture, Schizophonia, Soundscape, Recife.
\end{abstract}




\section{Introdução}

Com uma história baseada na desigualdade territorial, a cidade do Recife, hoje com 1.599.514 habitantes (IBGE, 2013), abriga vigorosas espessuras de fixos e fluxos geográficos ligados a manifestações musicais de cultura popular, entendidas como um conjunto de práticas erigidas nos lugares que intentam - num processo de conformismo e resistência - deflagrar o que a ideologia dominante quer esconder (Chauí, 1987). Propomos abordar as espessuras em torno dessas manifestações musicais que expressam a diversidade cultural do Recife.

Para tanto, tendo como entrada a difusão de informações no território da metrópole, destacamos Schafer (1997, p. 133), que nos traz a ideia de esquizofonia. A saber, a cisão entre procedência e difusão sonora engendrada a partir da criação do telégrafo, afastando os sons de seus contextos originais por meio da "transmissão ou reprodução eletroacústica." Trata-se de um conceito caro ao estudo da música e do som no período do meio técnico-científico-informacional (Santos, 1997).

A capital pernambucana, hoje o núcleo da Região Metropolitana do Recife (RMR), composta por catorze cidades, fora definida por Andrade (1979, p. 16) como "metrópole situada em região pobre da economia esclerosada”, constituída, em sua maioria, por uma população pouco especializada economicamente. Por outro lado, atualmente se destaca a diversidade e a riqueza cultural recifense, bem como a grande criatividade de sua população (Araújo, 2005). Fruto da mescla de hábitos e da lida num meio ambiente construído é resultante do improviso imposto pela situação de precariedade.

Ora, a "inchação", característica do centro de convergência para a população de uma área estagnada economicamente, tornou "a cidade que sai dentro da água” (Freyre, 1942, p. 74) abrigo para uma série de marginalizados, uma aglomeração urbana de contorno irregular, lugar de imbricação entre pobres e ricos.

Segundo Freyre (1978), a posição de sítio da cidade do Recife, à beira mar e açambarcada por dois rios, implicou num processo de urbanização e metropolização assinalado por abundantes e influentes contatos com outros lugares. Fato que, somado à mescla de povos abrigados na urbe, confere-lhe uma natureza essencialmente cosmopolita.

Não é por acaso que se deve sublinhar a impossibilidade de entender a música do Recife sem ter em mente a fusão de sons resultantes das tendências urbanas, que é o lugar receptor de indígenas, africanos, portugueses, 
holandeses, judeus, entre outros povos. A cultura negra, em especial, e toda a mescla entre os diferentes povos, conferiu à cidade e ao estado de Pernambuco uma grande diversidade de gêneros e estilos musicais. Dentre eles estão o maracatu, os caboclinhos, o afoxé, o cavalo-marinho e toda uma série de manifestações culturais de origem rural ou urbana que, em virtude da constante "inchação", desemboca na metrópole pernambucana.

Embora saibamos que muitos dos sons da cultura popular, que chamamos "não esquizofônicos" ou não elétricos, se utilizam hoje da eletricidade em suas apresentações - amplificadores para determinados instrumentos musicais, microfones para as vozes, entre outros objetos e sistemas técnicos são utilizados -, interessa-nos saber que tais sons surgiram e se disseminaram alheios às possibilidades trazidas pela esquizofonia. Acreditamos que, nesse fato, temos uma série de indicativos a respeito das situações de elaboração dessas manifestações culturais, parte delas de origem rural e outra, ainda que portadora da marca da urbanidade remete-nos a distintos períodos nos quais a força das formas-conteúdo tecno-científicas não preponderavam na dinâmica das cidades.

Procuramos erigir pontes entre a teoria e a concretude de objetos e ações, o empírico em suas contradições, possibilidades e lutas políticas (Ribeiro, 2003), focando a análise do território, visto como "um todo complexo onde se tece uma trama de relações complementares e conflitantes" (Santos et al., 2000, p. 3).

Premissa cara ao estudo do Recife, concordamos com Santos (1991) e Silveira (2011), quando consideram a grande cidade, a metrópole, o mais complexo espaço constituinte do conjunto de lugares onde a história se produz, chamado de território usado, logo, rica empiria ao desenvolvimento da reflexão sobre as possibilidades de comunicação no período atual. Malgrado o poder desigual de cada um de seus agentes, o território usado, "um quadro de vida" (Silveira, 2011, p. 35), base da vida cotidiana, abriga a todos e guarda a marca de seu tempo.

Abordar o cotidiano, alicerce do saber e da experiência diária, enquanto dimensão geográfica significa se acostar no lugar depositário das formas-conteúdo que encarnam o processo social. Ensina-nos Ribeiro (2005, p. 113) que o lugar abriga "uma complexa vida de relações que surge em práticas cotidianas”, tornando indispensável ao geógrafo conhecer a sua realidade.

Assim sendo, em nossa pesquisa, além do levantamento bibliográfico sobre a temática, foi essencial a composição de um campo de 
informação primária. Isso foi feito em visitas técnicas a lugares conformados e apropriados em torno dos sons não esquizofônicos - sedes de grupos de capoeira e de maracatu, escolas de samba, locais de ensaio, entre outros -, bem como por meio de entrevistas semiestruturadas realizadas juntos a agentes tais, quais artistas populares, produtores musicais, lideranças de bairro, entre outros. As informações resultantes do campo de informação primária serão assinaladas ao longo do texto com um asterisco.

O presente artigo está organizado em três partes. No primeiro momento, apresentamos informações sobre a tipologia e a topologia dos sons esquizofônicos na metrópole do Recife. Em seguida, destacamos as espessuras ligadas ao maracatu, enfocando o recente processo de "resgate" de uma das manifestações culturais mais significativas de Pernambuco. Por fim, abordamos a relação entre cultura popular e cotidiano, analisando a paisagem sonora (Schafer, 1997) do Bairro dos Coelhos, no Recife.

Trata-se de um trabalho com o intuito de contribuir para a análise do território usado a partir da dimensão cultural, destacando o papel dos lugares e de sua gente na constituição da urbe contemporânea.

Analisando a tipologia-topologia dos sons não esquizofônicos na metrópole do Recife

O olhar para as manifestações de gêneros não esquizofônicos, boa parte de ascendência negra, se mostra essencial ao estudo da atual dinâmica urbana recifense. Sejam suas variantes originais ou retrabalhadas, mescladas a gêneros, estilos e ritmos musicais “elétricos”, propondo o diálogo entre a tradição e a modernidade, trata-se de aspecto caro à produção musical no Recife e em Pernambuco, variáveis indispensáveis à análise da situação em torno cultura popular na metrópole contemporânea.

Nessa via, uma primeira questão se apresenta. De início, pensamos poder falar em sons de matriz negra. Contudo, a análise das manifestações não esquizofônicas nos mostra que, para além dessa importante e rica matriz, o Recife, assim como boa parte do Brasil, guarda várias outras matrizes.

De acordo com o Catálogo Música Recife (Recife, 2009), a cidade contaria com 18 manifestações de cultura popular, prescindindo da esquizofonia. Sete dessas manifestações são de origem predominantemente negra, como os maracatus ou os afoxés, enquanto outras onze manifestações guardariam uma mescla mais ampla de povos em sua gênese e evolução, caso, entre outros, da ciranda ou do pastoril (Tabela 1). 
Quadro 1 - Manifestações de "cultura popular" - não esquizofônicas

\begin{tabular}{|c|}
\hline Manifestações negras \\
\hline $\begin{array}{c}\text { Maracatu de Baque Virado, Maracatu de Baque Solto, Bloco de Samba, } \\
\text { Escola de Samba, Grupo de Samba Reggae, Afoxé, Bloco Afro. }\end{array}$ \\
\hline Outras manifestações \\
\hline $\begin{array}{c}\text { Caboclinhos, Cavalo-Marinho, Forró, Ciranda, Coco, Pastoril, Bloco de } \\
\text { Pau e Corda, Clube de Boneco, Mascarado, Troça, Urso. }\end{array}$ \\
\hline
\end{tabular}

Fonte: Catálogo Música Recife (2009).

Elaboração própria, 2014.

Nosso levantamento aponta consideráveis espessuras em torno das diversas manifestações não-esquizofônicas no Recife e em Pernambuco (Gráfico 1). Desde o forró e a sua desenvolvida forma de organização, passando pelo frevo, emergente em especial no período carnavalesco, até a ciranda, tais manifestações dão um colorido peculiar à dinâmica sonora do estado e de sua capital anfíbia (Freyre, 1942).

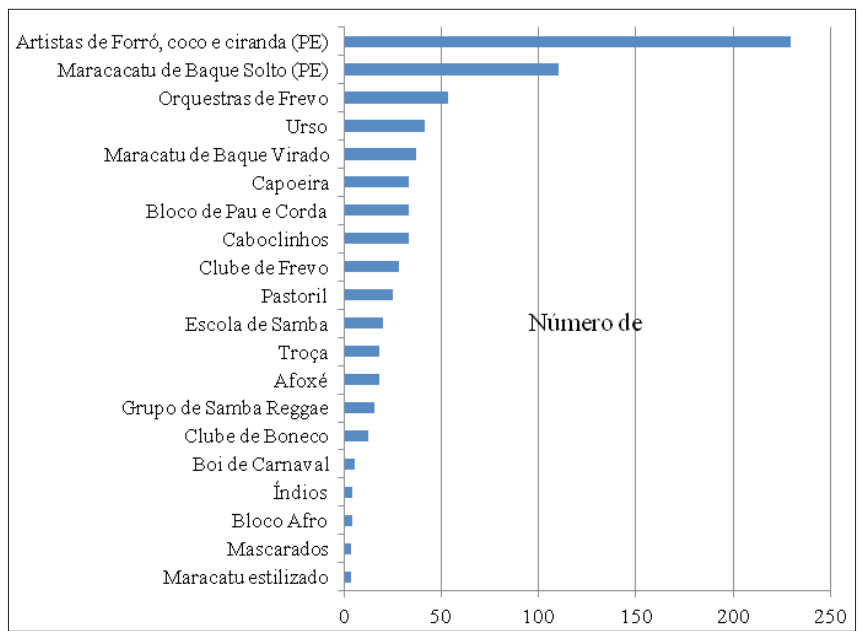

Figura 1 - Manifestações não esquizofônicas na RMR e em Pernambuco

Fonte: Guia Música Recife - PMR (2008-2009)/ Recife Nação Africana - Silva (Org.) - Recife, Prefeitura Municipal, 2008.

Elaboração própria, 2014. 
Cartografamos as informações relativas às manifestações não esquizofônicas na Região do Recife (Figuras 1, 2, e 3). As sedes dos maracatus e afoxés (Figura 1) se concentram nos Morros da Zona Norte do Recife (lugares como Macaxeira, Dois Unidos, Casa Amarela, Pinho e Santa Terezinha). Destacam-se ainda concentrações em Afogados, Pina e nos subúrbios na zona norte de Olinda (caso de Rio Doce).

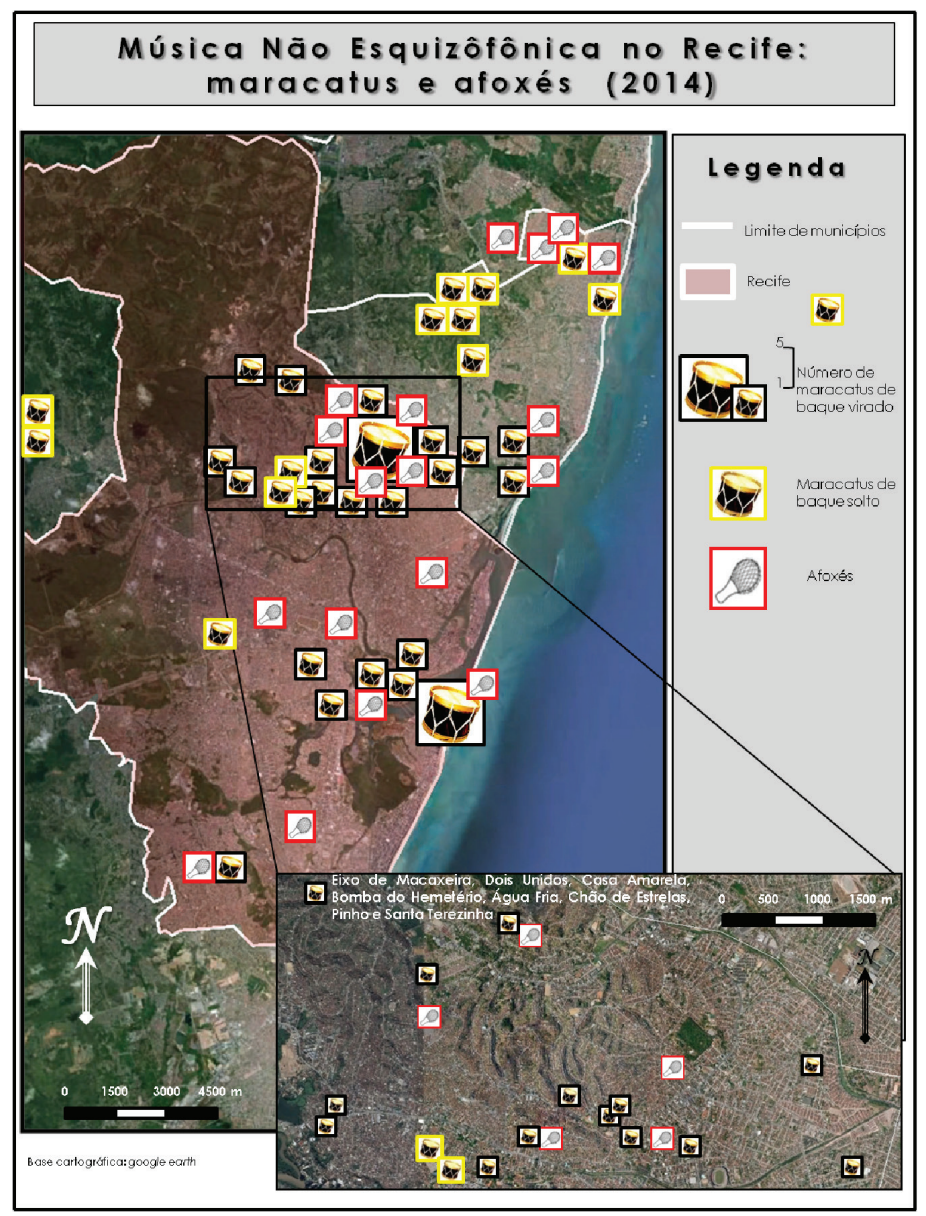

Figura 2 - Macaratus e afoxés no Recife Fonte: Informações primárias; Silva (2008). Elaboração própria, 2014. 
As manifestações de capoeira e samba (Figura 2) se concentram e se estendem desde os Morros da Zona Norte do Recife, passando pelos bairros de baixa renda e mocambos na área central do Recife, alcançando Afogados. Destaca-se uma concentração de blocos de samba em Santo Amaro.

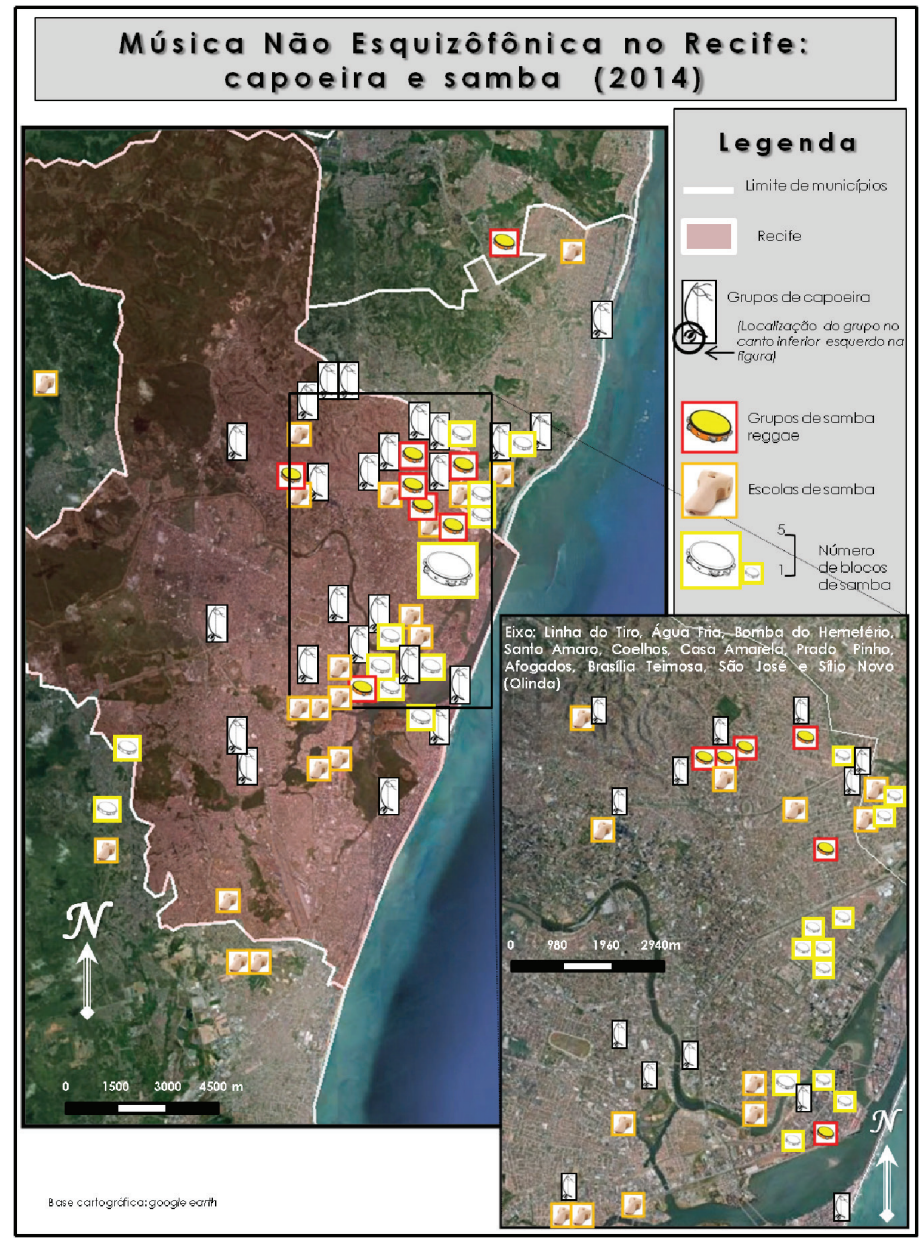

Figura 3 - Capoeira e Samba no Recife

Fonte: Informações primárias; Silva (2008). 
Grosso modo, os caboclinhos, os clubes de frevo e os clubes de boneco (Figura 3) apresentam uma topologia semelhante aos grupos de capoeira e samba. Todavia, com um maior destaque para as manifestações abrigadas em Afogados e Imbiribeira.

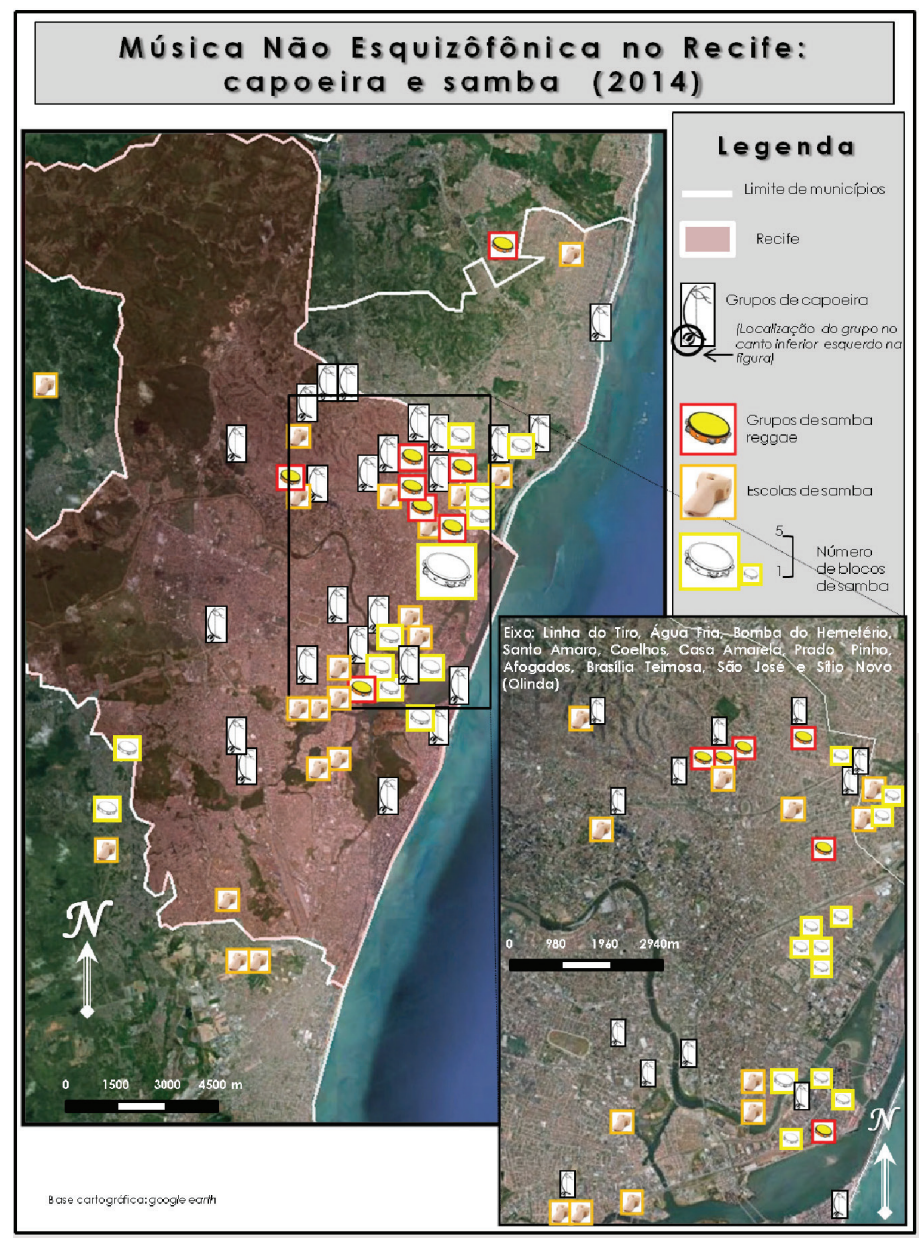

Figura 4 - 0 maracatu em Recife: queda e ascensão da cultura popular Fonte: Informações primárias; Silva (2008). 
A topologia das manifestações não esquizofônicas na Região do Recife aponta para os nexos entre os espaços opacos da metrópole (Santos, 1997), onde predomina a precariedade de bens e serviços essenciais à condição cidadã, e as manifestações da cultura popular.

0 maracatu em Recife: queda e ascensão da cultura popular

O maracatu se divide em dois gêneros: de baque solto e baque virado. De acordo com Neto (1997, p. 22), os maracatus rurais "sofreram uma verdadeira agressão cultural, obrigados sob pressão (pela desinformação preconceituosa, dizemos nós) da Federação Carnavalesca Pernambucana a se tornarem de Baque-Virado, adotando o ritmo dos maracatus-Nações, urbanos, recifenses.” Além da presença do caboclo de lança, musicalmente falando, os maracatus rurais se distinguem dos maracatus de baque-virado por tocarem "vários ritmos, como coco, baião, samba e frevo, das toadas de improviso dos emboladores (daí a denominação, de 'baque solto')", e terem na orquestra instrumentos como o trompete, o saxofone e o clarinete.

Ainda sobre os maracatus, faz-se necessário distinguir as nações e os grupos percussivos. Assim, lançamos mão da proposta de Lima (2009), para quem:

O maracatu-nação constitui parte de uma grande cultura negra que foi construída e é vivida neste país, ao passo que o grupo percussivo pode ser observado e conceituado como uma prática cultural brasileira, sem que necessite de outro adjetivo para ser devidamente entendida e analisada (Lima, 2009, p.23).

Nesse raciocínio, a ideia de nação teria menos uma ligação direta com uma religião, um terreiro em comum, e mais com as práticas, hábitos e costumes compartilhados pelos maracatuzeiros num determinado entorno. Em suma: o convívio e a troca cotidiana entre os agentes é o que distingue a nação do grupo percussivo. Ainda de acordo com Lima (2009), a RMR abrigaria hoje cerca de 100 grupos percussivos e trinta nações de maracatu.

A situação atual destoa da descrita com o argumento de que o maracatu em meados dos anos 1980 estava virtualmente morto, algo recorrente em nosso campo de informação primária*. A esse respeito, constata-se que um terço dos 33 maracatus de baque virado da RMR 
surgiu no período pós 1988, enquanto dos 103 maracatus de baque solto de Pernambuco, 58 deles foram criados no período pós 1986.

Entre outros interlocutores, o produtor musical Fábio Cabral, da Gravadora Passa Disco*, afirma que "se tinha vergonha do maracatu”, algo lembrado apenas durante o carnaval. Daí uma reportagem do Suplemento Cultural, de janeiro de 1989, dar conta da luta dos maracatus para sobreviverem frente à falta de recursos para os cortejos de carnaval, à incerteza sobre o futuro de suas sedes e à venda de nações inteiras para particulares, caso do Maracatu Elefante.

No processo de resgate do maracatu, deve-se destacar a ação da Nação Pernambuco, um grupo de universitários e jovens da classe média da região do Recife (Japiassu, 1991), atuante desde os anos 1980, que pôs em movimento o que até então era uma tradição não apenas cristalizada, mas praticamente paralisada. Tratou-se de um tortuoso processo de conflito e negociação com os mestres da cultura popular, tendo sido importante, entre outros, a ação de Ivaldo Lima, hoje professor de História, figura ativa no "resgate" dos maracatus.

Não por acaso, o Maracatu Nação Pernambuco esteve presente na Primeira Edição do Festival Abril Pro Rock, em 1993, em meio à ebulição da Cena Manguebeat, marcada pela fusão sonora entre sons elétricos e de matriz negra e capitaneada por bandas como Mundo Livre S/A, Chico Science e Nação Zumbi. O idealizador do Festival, Paulo André*, pondera que o convite para que o Maracatu tocasse no Festival se deu em resposta à atuação do grupo, contribuindo para o "processo de valorização da música popular pernambucana pelos jovens", declara o produtor.

Apesar do adensamento em torno dos maracatus e malgrado à forte presença na região de inúmeras manifestações não esquizofônicas, Evandro Sena*, coordenador de música da secretaria de Cultura da Prefeitura Municipal do Recife, e Rafael Cortes*, coordenador de música da Fundação do Patrimônio Histórico e Artístico de Pernambuco (Fundarpe), pontuam que os agentes ligados à música tradicional, ou não esquizofônica, se mantêm graças ao sistema de incentivo e aos pontos de cultura, muitos deles em condição de "miserabilidade."

Nessa via, os órgãos públicos estabelecem, entre outros, editais específicos para "grupos que trabalhem com as tradições ou ressignifiquem as tradições de carnaval”, sublinha Evandro Sena*. Tanto Evandro quanto Rafael $^{*}$, ambos os gestores culturais, acreditam que o fortalecimento da chamada “cultura popular” se deve em grande parte à Cena Manguebeat. 
Para Lima e Guillen (2007), um conjunto de fatores para além da Cena Manguebeat deve ser levado em consideração para entender os motivos do adensamento em torno dos maracatus. Merece destaque a obstinação dos maracatuzeiros e maracatuzeiras e o fortalecimento do Movimento Negro Unificado no Recife, a partir dos anos 1980, "a exemplo da conjugação entre turismo, gosto pelo exotismo das culturas populares e crescimento mundial do consumo do que se convencionou denominar world music" (Lima e Guillen, 2007, p. 12).

O fato é que hoje os ensaios de grupos e nações de maracatu, entre outros, recebem inúmeros turistas, como pudemos observar pela dinâmica das ruas ou de locais, tais como o Mercado Eufrásio Barbosa em Olinda. Nele, durante as tardes, sobretudo nos finais de semana, ocorre ensaios de afoxés ou maracatus.

Todavia, são os grupos percussivos que gozam de maior visibilidade e se disseminam no país e fora dele. Pesa a favor deles o poder de articulação. Existem grupos por todo o Brasil e em países como Alemanha, EUA, Rússia, França, Inglaterra, Japão e Canadá, dentre outros (Lima, 2009).

\section{0 bairro dos Coelhos: cultura popular, paisagem sonora e desigualdade socioterritorial}

Propomos transitar da paisagem geográfica, uma das categorias de análise do espaço, entendida como o conjunto de volumes, sons, odores, cores, entre outros, que o nosso aparelho perceptivo pode captar (Santos, 1988), rumo à paisagem sonora (Schafer, 1997; Martignoni, 2006), noção que designa "um campo de interações" criado pela simultaneidade e o intercâmbio de eventos sonoros situados nos lugares (Schafer, 1997, p. 185). Em busca das espessuras sonoras do lugar em sua relação com o cotidiano da urbe, visitamos o Bairro dos Coelhos, uma das Zonas Especiais de Interesse Social (ZEIS) do Recife, entre outros, abrigo de uma escola de samba e uma nação de maracatu.

A presidente da Escola de Samba Gente Inocente, Dona Ivonete, natural de Pesqueira-PE, e há mais de 70 anos nos Coelhos, fala da origem do bairro* a partir de sucessivos aterramentos feitos à mão ao longo dos anos:

...aqui já foi um cemitério (...) quando eu cheguei isso aqui era tudo maré, isso aqui foi tudo aterrado, tu sois doido morar aqui dentro d'água, eu botava os aterros todo aqui, dava o almoço e o pessoal do caminhão (da prefeitura) trazia o aterro pra lá. A luz vinha da Rua Imperial... 
Os braços e as mãos desenvolvidas de Dona Ivonete dão ideia do quanto o seu corpo agiu contra a força das águas do Rio Capibaribe. O corpo de Dona Ivonete luta de modo igual contra as dificuldades para colocar a escola de samba remanescente do bairro no desfile de carnaval. Em meio às dificuldades financeiras da escola, composta por 600 integrantes, em sua maioria crianças do bairro, às vésperas do carnaval de 2011, Dona Ivonete*, que afirma não pedir de modo algum dinheiro nas "portas das casas", havia comprado com seus próprios recursos 50 bermudões a cinco reais cada, evitando que não houvesse fantasia para a bateria. Isso implicou em reprimendas por parte de seus familiares, pessoas de poucos recursos financeiros: "a minha filha falou: mãe você tá louca! Mas o som, a festa, isso é uma doença!", explica a presidente da "Escola da Cegonha" como, é conhecida a agremiação.

Bia da Creche*, presidente da Associação de Bairros, no ano de 2011, e moradora dos Coelhos há 48 anos, complementa: "Tem que ter muita garra (...) pois o incentivo é uma quantia insignificante, para cada um dos grupos, pois se gasta com carros, fantasia, uma porção de coisas...”. Apuramos que a quantia recebida da Prefeitura Municipal do Recife, caso o grupo tenha CNPJ (Cadastro Nacional de Pessoa Jurídica), é da ordem de três mil reais anuais, ao passo que $\mathrm{R} \$ 380,00$ são destinados aos grupos sem o referido cadastro.

Reinaldo, uma das lideranças do bairro, puxador de samba da agremiação, afirma*: "O carnaval é pra ver o povo brincar", um esforço no sentido de tirar as crianças da rua, "ou rica ou pobre a escola vai sair e as crianças ficarão felizes".

Por outro lado, relacionado ao fenômeno de migração sublinhado por Neto (1997, p. 22), para quem os maracatus 'modernos' são resultado do "êxodo rural que desde a terceira década deste século XX vem inchando as ruas, os alagados e os morros da área metropolitana", visitamos, nos Coelhos, o Maracatu Rosa Vermelha. Composta por 80 integrantes, metade deles batuqueiros, a Nação, sediada num salão anexo à residência de Samuel, um de seus mestres, toca com instrumentos confeccionados pelos seus próprios integrantes, caso das alfaias, que podem ficar prontas após cinco horas de trabalho e, se for o caso, vendidas por $\mathrm{R} \$ 500,00$ cada.

Observamos, num sábado e num domingo à tarde, o "duelo sonoro". Consiste em uma miscelânea em alto volume, oriunda de carros, aparelhos de som, todos em ação nas casas, nas ruas e nas vielas, devido à configuração territorial do bairro, bem próximas umas das outras. 
Pensando na paisagem sonora do lugar, conversamos com foliões do Bloco dos Chifrudos e com dirigentes de uma igreja evangélica do bairro, que, entre outros, oferece cursos de música aos fiéis e uma rádio livre. O locutor da emissora, Lindolfo, conta* que o veículo informacional funciona com a colaboração de anunciantes locais (entre eles o Maraca Suco, Fominha Lanches ou Armazém Veras).

Com o auxílio de pequenos patrocinadores, funciona também o Projeto Acorda Povo. Constitui-se em encontros nos finais das madrugadas durante todo o carnaval, regados à cerveja e comida, tudo ao som de uma orquestra de frevo. Os agentes do bairro dizem* que, em troca de propagandas em camisetas, recolhem caixas de cervejas dos patrocinadores, ao passo que os moradores se encarregam da comida e do pagamento da orquestra: em torno de $\mathrm{R} \$ 900,00$ reais para a apresentação de 12 músicos por um período de duas horas.

Entre os problemas dos Coelhos, enfatiza Bia*, por conta da Copa do Mundo de Futebol 2014 e do Projeto Via Mangue, 800 famílias do entorno foram desabrigadas, no intuito de "esconder" em especial o conjunto de palafitas visíveis nas pontes que fazem a ligação com Santo Antônio, área central do Recife.

Sobretudo as áreas mais novas do bairro, na beira do Rio Capibaribe, sofrem frequentemente com sinistros. Fato esse que implica num auxílio, por parte do poder público, no valor de R 700 por unidade residencial: “é para as pessoas comprarem as suas coisas de volta?”, indaga a liderança, Bia da Creche*.

Com frequência, aos aterramentos se segue a chegada de agentes influentes que alegam posse do terreno recém-surgido. Um dos moradores* $^{*}$ nos conta de uma área que acabara de sofrer um sinistro, na qual sobraram apenas os “jacarés”, ligações de água improvisadas em canos de reduzido diâmetro.

Seguindo com tema, para Santos (1997), uma entrada analítica ao estudo dos lugares, dar-se-ia a partir das horizontalidades, vetores de proximidade, e das verticalidades, imposições de lógicas externas. De acordo com Moreira (2007, p. 60), trata-se, o lugar, de um "fruto da rede", onde, qualquer que seja a atividade, engendra-se um "todo orgânico do ponto de vista da horizontalidade”, signo da capacidade de aglutinação.

Nessa via, além das variáveis verticais, dinamizam-se, no bairro, horizontalidades responsáveis por desequilíbrios. É o caso do aluguel de 
barracos por parte de moradores com mais de uma casa, cujo valor gira em torno de $\mathrm{R} \$ 100,00$.

Por fim, destaca-se que no bairro é grande o índice de usuários de crack, não apenas entre os jovens. Outro problema, destacado por Reinaldo*, é a falta de postos de emprego. Segundo ele, no Recife esses postos existem apenas para pessoas especializadas em alguma função, o que não é o caso da massa dos moradores do entorno.

\section{Considerações finais}

A análise das manifestações de cultura popular tomando como entrada a noção de esquizofonia, auxilia-nos a pensar o território usado e a dimensão cultural numa relação direta com o desenvolvimento dos sistemas técnicos instrumentais e a difusão da informação. De que modo tais manifestações, surgidas a despeito dos sistemas técnicos informacionais, ainda permanecem como variáveis essenciais ao entendimento da dinâmica urbana contemporânea?

Constatamos na metrópole do Recife a existência de 18 tipos de manifestações de sons não esquizofônicos, observando-se uma forte influência negra, destacando-se, sobretudo as espessuras em torno do forró, coco, ciranda, maracatu e frevo. Preponderam, como abrigo para os sons não esquizofônicos, os morros da zona norte do Recife, a Região de Afogados e os mocambos no entorno do centro da cidade, como os existentes em Santo Amaro.

O recente adensamento das espessuras ligadas ao maracatu demonstra, entre outros, o modo como ganha corpo, no Recife, a presença da cultura popular no cotidiano da metrópole. Ora, o exame do Bairro dos Coelhos explicita bem o cotidiano de uma metrópole corporativa e fragmentada (Santos, 1990), assolada por uma pobreza estrutural. Todavia, é abrigo da riqueza cultural, plena de diversidade e de espessuras ascendentes, assentadas nos lugares.

A riqueza cultural presente no cotidiano do Recife leva-nos a afirmar que abdicar de práticas, saídas e propostas baseadas em nossa realidade espacial significa dar continuidade ao processo de colonialismo, assumindo a posição reticente do colonizado. O saber, o improviso, a diversidade de experiências e materiais são a riqueza do chamado terceiro mundo, parcela de um sistema à margem das decisões políticas e econômicas que culminaram na dinâmica atual do sistema mundo. 
Trata-se de uma vasta e complexa agenda de pesquisa, necessária ao desenvolvimento de alternativas, buscando usos do território menos desiguais no período contemporâneo.

\section{Nota}

Artigo resultante de pesquisa de doutorado financiada pela CAPES (Março de 2010/Fevereiro de 2014).

\section{Referências}

ANDRADE, M. C. Recife - Problemática de uma metrópole da região subdesenvolvida. Recife: Editora Universitária - UFPE, 1979.

ARAÚJO, T. B. A dinâmica regional brasileira e o Recife In: REYNALDO, A. (Org.). Metrópole estratégica - Região Metropolitana de Recife. Recife: CONDEPE/ FIDEM, Prómetrópole, 2005. p. 21-37.

CHAUÍ, M. Conformismo e resistência: aspectos da cultura popular no Brasil. São Paulo: Brasiliense, 1987.

FREYRE, G. Guia prático, histórico e sentimental do Recife. Rio de Janeiro: José Olimpo, 1942.

. Em torno do processo de urbanização do Recife: perspectivas históricas. URBIS, Revista de Urbanismo e Desenvolvimento, v. 1, n. 1, p. 24-35, 1978.

IBGE (INSTITUTO BRASILEIRO DE GEOGRAFIA E ESTATÍSTICA). Estimativa populacional dos municípios brasileiros. Disponível em: <http://www.ibge.gov. br/>. Acesso em: 9 dez. 2013.

JAPIASSU, R. Recife: centro fonográfico? Suplemento Cultural, Diário Oficial de Pernambuco, out. de 1991, p. 14-15.

LIMA, I. M. F.; GUILLEN, I. C. M. Cultura afro-descendente no Recife: maracatus, valentes e catimbós. Recife: Bagaço, 2007.

LIMA, I. M. F. Identidade negra no Recife: maracatus e afoxés. Recife: Bagaço, 2009.

MARTIGNONI, A. Objets et paysages sonores. Geógraphie et Cultures, n. 59, p. 127-133, 2006.

MOREIRA, R. Da Região à rede e a lugar: a nova realidade e o novo olhar geográfico sobre o mundo. ETC: Espaço, tempo e crítica, vol. 1, n 1(3), p. 55-70, 2007.

NETO, O. B. Breve informe sobre os maracatus. Suplemento Cultural, Diário Oficial de Pernambuco, fev. 1997. p. 22. 
RECIFE. Prefeitura Municipal do Recife. Catálogo Musica do Recife. 2009.

RIBEIRO, A. C. T. Pequena reflexão sobre categorias da teoria crítica do espaço: território usado, território praticado. In: SOUZA, M. A. (Org.). Território Brasileiro: usos e abusos. Campinas: Edições Territorial, 2003. p. 29-40.

RIBEIRO, A. C. T. O desenvolvimento local e a arte de 'resolver' a vida. In: LIANZA, S.;

ADDOR, F (Org.). Tecnologia e desenvolvimento social e solidário. Porto Alegre: Editora da UFRGS, 2005. p. 109-120.

SANTOS, M. Metamorfoses do espaço habitado. São Paulo-SP: Hucitec, 1988. . Metrópole Corporativa e Fragmentada: o caso de São Paulo. São Paulo: Secretaria de Estado da Cultura, 1990.

. A revolução tecnológica e o território: realidades e perspectivas. Cáderno Prúdentino de Geografia. n. 13, p. 141-152, 1991.

Hucitec, 1997.

. A natureza do espaço: técnica e tempo, razão e emoção. São Paulo:

SANTOS, M. et al. O papel ativo da geografia: um manifesto. Florianópolis: XII Encontro Nacional de Geógrafos, 2000.

SCHAFER. R. M. A afinação do mundo - uma exploração pioneira pela história passada e pelo atual estado do mais negligenciado aspecto do nosso ambiente: a paisagem sonora. São Paulo: Unesp, 1997.

SILVA, C. (Org.). Recife nação africana. Recife: CEPE, 2008.

SILVEIRA, M. L. Economia Política e ordem espacial: circuitos da economia urbana. In: SILVA, C. A. (Org.). Território e ação social: sentidos da apropriação urbana. Rio de Janeiro: Faperj/Lamparina, 2011. p. 35-51.

Cristiano Nunes Alves - Possui Bacharelado e Licenciatura em Geografia pela Universidade Estadual de Campinas. É Mestre e Doutor em Geografia pela mesma instituição. 